\title{
Migraine and Obesity in Parakou in 2017: Case-Control Study
}

\author{
Adoukonou Thierry ${ }^{1 *}$, Agbétou Mendinatou ${ }^{1}$, Gahou Aude ${ }^{1}$, \\ Sossou Charles Bohr'1, Houinato Dismand ${ }^{2}$
}

\author{
${ }^{1}$ Department of Neurology, Faculty of Medicine, University of Parakou, Parakou, Benin \\ ${ }^{2}$ Department of Neurology, Faculty of Health Sciences, University of Abomey-Calavi, Abomey-Calavi, Benin \\ Email: *adoukonouthierry@yahoo.fr
}

How to cite this paper: Thierry, A., Mendinatou, A., Aude, G., Bohr, S.C. and Dismand, H. (2018) Migraine and Obesity in Parakou in 2017: Case-Control Study. Pain Studies and Treatment, 6, 15-23. https://doi.org/10.4236/pst.2018.63003

Received: July 1, 2018

Accepted: July 27, 2018

Published: July 30, 2018

Copyright $\odot 2018$ by authors and Scientific Research Publishing Inc. This work is licensed under the Creative Commons Attribution International License (CC BY 4.0).

http://creativecommons.org/licenses/by/4.0/

\section{(c) (i) Open Access}

\begin{abstract}
Objective: We aim to study the relationship between migraine and obesity at Titirou in Parakou in 2017. Method: It was a case-control study which included 66 migrainers according to International Headache Society (IHS) criteria 2013 (case) matched to 132 controls by age, sex and residence. Size and weight have been measured in each subject. Body mass index has been calculated. Migraine history and sociodemographic information have been collected from $1^{\text {st }}$ May to $31^{\text {st }}$ August 2017 and analyzed by using Epi Info 7 software. The association between migraine and obesity was estimated by odds ratio and their confidence interval. Results: There has been no difference among those suffering from migraine and controls according to sociodemographic characteritics. Obesity has significantly been associated with migraine with OR $4.24(1.93$ - 9.25). The weight more than $70 \mathrm{Kg}$ has been associated with the migraine with OR: $2.02(1.06-3.90)$. The overweight and obesity have been associated with migraine OR with respectively 1.9 (1.1 - 3.9) and 4.4 (2.0 - 9.5). No difference has been found between migraine and the clinical characteristics of migraine (type, severity, intensity). Conclusion: Obesity has been associated with migraine and has to be taken into account in migraine management.
\end{abstract}

\section{Keywords}

Migraine, Obesity, Epidemiology, Case-Control Study

\section{Introduction}

Obesity and migraine affect many people around the world and are responsible for disability and impairment of quality of life. More than a billion adults worldwide are obese according to World Health Organization, WHO [1], while 
headache affects $47 \%$ of people around the world with $10 \%$ of migraine [4]. These conditions have sexual dismorphism, affecting women more than men and linking to estrogen and hormonal life-cycle [3] [4]. They share physiopathological mechanisms, such as hypothalamic involvement in several headache disorders, including migraine [5] [6]. Also orexin and serotonin has been linked to migraine and feeding. The peptides, neurotransmitters and adipocytokines, such as adiponectin and leptin participate in energy homeostasis, regulation of feeding, have been suggested to be altered in migraineurs [7] [8]. Expansion of adipose tissue during weight gain leads to the recruitment of macrophages and $\mathrm{T}$-cells, and directly results in the induction of adipocytokines and expression of several proinflammatory cytokines [9], including IL-1, IL-6, and tumor necrosis factor (TNF)- $\alpha[10]$.

Global prevalence of migraine is $12 \%$ of the general population according to the "strict" criteria of international headache society (IHS); $21 \%$ including patients with probable migraine [2] [11]. Obesity is a risk factor for headache in general, as well as for episodic migraine and chronic migraine specifically [12] [13]. Some studies have shown that the odds of migraine or severe headache have been increased by approximately 39\% in woman of reproductive age with total body obesity TBO (OR 1.39; CI: 1.24 - 1.56) [14]. While other studies have found no association between migraine prevalence and total body obesity in women, or a decreased prevalence of migraine in women with abdominal obesity in peri- and post-menopausal women between 40 and 74 years of age, with a mean age of 54 years [14].

This study has been conducted in order to point out the influence of obesity on migraine in the general population in North Benin.

\section{Methods}

Type of study: It was an observational case-control study with a descriptive and analytical focus.

Collection period: The data collection took place over a period of three (3) months from May 1 to August 31, 2017.

Inclusion Criteria: The respondents were selected on the basis of the following criteria:

For the cases:

- subjects living in TITIROU

- who gave there consent

- who were present on the day of the survey

- age to 18 years at least to 65 years at the most

- the diagnosis of migraine was made according to IHS criteria

For the witnesses. They were matched to the case by age \pm 1 year, sex and residence.

Non-inclusion Criteria:

- subjects who have not given their consent 
- residents who work at Titirou without living there

- pregnant women

\section{Sampling:}

1) For the migraine sufferers

It was a non-probabilistic method with a comprehensive sampling technique. The migraine patients in our sample were taken from a neuroepidemiological survey (the door-to-dor survey) on the prevalence of migraine at Titirou in 2017. They fulfilled the IHS strict criteria of 2013 (IHS, Cephalalgia 2013). At least 5 attacks fulfilling criteria 2) - 4).

Headache attacks lasting 4 - 72 hours (untreated or unsuccessfully treated).

Headache has at least two of the following 4 characteristics:

a) Unilateral location.

b) Pulsating quality.

c) Moderate or severe pain intensity.

d) Aggravation of pain by routine physical activity.

During headache at least one of the following:

a) Nausea and/or vomiting.

b) Photophobia and phonophobia.

2) For the subjects control

Two subjects control were chosen from the same house or the neighbouring house according to the matching criteria.

3) The Sample size

The sample size was calculated assuming an odds ratio between cases and controls of 3, risk of first species was 0.05 and risk of second species $20 \%$ (power $80 \%$ ). Two (2) controls per case with a prevalence of migraine three (3) times higher in obese subjects, and an obesity prevalence of $11 \%$ were used as the base of calculation. It was thus obtained using the Epitable software of Epi-Info version $6.04 \mathrm{C}$, a minimum of 63 cases and 126 controls.

\section{Variables}

Dependent variables: This was a case-control study; the disease here is migraine; dichotomous variables with two modalities (yes for cases and no for controls), the main exposure studied is obesity defined by BMI $\geq 30$.

Independent variables are sociodemographic (age, gender, religion, ethnic, marital status, level of education, nationality, profession), anthropometric parameters, weight (dichotomous variable with modalities: $\geq 70$ and $<70$ ); size (dichotomous variable with modalities: $\geq 1.70 \mathrm{~m}$ and $<1.70 \mathrm{~m}$ ); Body Mass Index (BMI) with four (4) modalities: <18.5 (thinness) 18.5 - 24.9 (normal) 25 - 29.9 (overweight) $\geq 30$ (obesity).

The clinical characteristics of migraine (intensity and frequency of headaches, type of migraine) were collected.

\section{Data collection}

Tools

We used a questionnaire, SECA $^{\circledR}$ brand weight scale for weight gain, 
Centimeter graduated for taking the size.

\section{Technique}

It was structured individual interview. Each subject was submitted to a pre-established questionnaire. This questionnaire consisted of many parts: the first part was related to sociodemographic data, the second explored the characteristics of migraine with possible triggers, a third part for the antecedents; the last part collected anthropometric and clinical data (weight, height, abdominal perimeter, blood pressure). Most of the questions were grouped under the term spontaneous evocation for open questions and evocation on indication for closed ones. After interview, weight was taken, size measured and BMI calculated. The weight was taken in a room of the home by a scale SECA type with an accuracy of $100 \mathrm{~g}$. All subjects were lightly dressed with respect for privacy. The size was taken with a measure (precision of $0.1 \mathrm{~cm}$ ) in all subjects previously barefooted and without hat.

\section{Data Analysis}

Means with a standard deviation were calculated for the quantitative variables (age, weight, height, blood pressure). Frequencies were calculated for all qualitative variables. The $\chi^{2}$ test (or Fisher's exact test as appropriate) was used for comparisons between dependent and independent variables, and Student's test for comparison of means. Association between migraine and obesity or other characteristics was studied by calculating the odds ratio (OR) and their confidence interval at $95 \%$. This association was considered significant when $\mathrm{p}$ was $<0.05$.

\section{Ethical considerations}

Approval of the Local Committee of Ethics in Biomedical Research of the University of Parakou (CLERB-UP), authorization from the municipal authorities and those of the district of Titirou, oral consent of respondents were obtained. We guaranteed confidentiality to our respondents and we collected the data in strict respect of anonymity.

\section{Results}

\section{Sociodemographic characteristics}

Age and sex were distributed in the same proportion in migraine patients as non-migraine sufferers with an average age of $31.87 \pm 8.37$ (18 - 65) years. In both groups, subjects aged from 20 to 29 years were more numerous with a frequency of $45.45 \%$. The sex ratio was 0.43 with a predominance of women (69.70\%). In migraine patients, student and apprentice students were the most numerous, while among non-migraine sufferers there was a predominance of traders. The two groups were similar in terms of marital status; subjects in couples were $40(60.61 \%)$ in migraine patients and 76 (57.58\%) in non-migraine patients; then single subjects $23(34.85 \%)$ in migraine patients and $53(40.15 \%)$ in non-migraine patients. Finally, few migraineurs or non-migraine subjects were widowed 3 in each groups (respectively $4.55 \%$ and $2.27 \%$ ). 


\section{Anthropometric characteristics}

\section{Weight and size}

The average weight of the respondents was $68.40 \pm 9.85(43-110) \mathrm{kgs}$ and subjects between 50 and 90 kgs were majority. The average size was $1.67 \pm 0.07$ $(1.45-1.87) \mathrm{m}$.

\section{$B M I$}

A normal BMI was found in 86 subjects (43.43\%); average BMI was $24.68 \pm$ $3.23(17.60-45.70) \mathrm{kg} / \mathrm{m}^{2}$.

\section{Clinical features of migraine}

Among the 66 migraineurs, more than half 37 (56.06\%) had a migraine with aura; scotoma $(48.65 \%)$ or phosphene $(27.03 \%)$ are the most freqent type of aura. Headaches intensity were extremely high in 4 subjects $(6.06 \%)$, strong in 20 subjects (30.30\%) and moderate in the remaining 42 migraineurs (63.64\%).

\section{Migraine and associated factors}

Migraine was associated with the weight $(\mathrm{p}=0.0208)$. Subjects with a weight greater than or equal to $70 \mathrm{kgs}(41 \%$ or $62.12 \%)$ have more migraine than the other subjects with a lower weight $(25 \%$ or $37.88 \%)$. There were twice as likely to make it $\mathrm{OR}=2.02)$. There was no statistically association between migraine and size $(\mathrm{p}=0.8171)$, but subjects less than $1.70 \mathrm{~m}$ tall $(50 \%$ or $75.76 \%)$ have more migraine like summarized in Table 1.

There was a significant association between migraine and BMI with a $\mathrm{p}$ value at 0.0019 . There were more migraine sufferers among obese subjects $24(36.36 \%)$ and overweight subjects $23(34.85 \%)$ and the risk of migraine increases with BMI. Most of non-migraine subjects had a normal BMI (50.76\%). Comparison of average of anthropometric parameters are summarized in Table 2. Table 3 summarized the association between migraine and body mass index.

Obesity was neither associated with the number of crisis of the last month nor with that of the last 6 months. The intensity of migraine attacks was not associated with obesity and there was also no association between obesity and migraine type $(\mathrm{p}=0.7785)$. Those data were summarized in Table 4 .

\section{Discussion}

In our study obesity predominates in women. Similarly, a sexual dimorphism is

Table 1. Association between migraine, weight and size, Parakou 2017.

\begin{tabular}{|c|c|c|c|c|c|c|c|}
\hline & \multicolumn{2}{|c|}{ Migraine } & \multicolumn{2}{|c|}{ No migraine } & \multirow{2}{*}{ OR } & \multirow{2}{*}{$\mathrm{IC}_{95 \%}$} & \multirow{2}{*}{$\mathrm{p}$} \\
\hline & $\mathrm{n}$ & $\%$ & $\mathrm{n}$ & $\%$ & & & \\
\hline Weight (kg) & & & & & & & 0.0208 \\
\hline$\geq 70$ & 41 & 62.12 & 59 & 44.70 & 2.02 & $(1.06 ; 3.90)$ & \\
\hline$<70$ & 25 & 37.88 & 73 & 55.30 & 1 & & \\
\hline Size (m) & & & & & & & 0.8171 \\
\hline$\geq 1.70$ & 16 & 24.24 & 34 & 25.76 & 0.95 & $(0.43 ; 1.91)$ & \\
\hline$<1.70$ & 50 & 75.76 & 98 & 74.24 & 1 & & \\
\hline
\end{tabular}


Table 2. Comparison of anthropometric parameters between migraine sufferers and no migraine, Parakou 2017.

\begin{tabular}{cccccc}
\hline & \multicolumn{2}{c}{ Migraine } & \multicolumn{2}{c}{ No migraine } & \multirow{2}{*}{$\mathbf{p}$} \\
\cline { 2 - 5 } & Min-Max & Mean $\left(\mathrm{SD}^{*}\right)$ & Min-Max & Mean $\left(\mathrm{SD}^{*}\right)$ & \\
\hline Weight & $50-105$ & $\mathbf{7 4 . 6 1 ( 1 2 . 8 5 )}$ & $43-103$ & $\mathbf{6 8 . 7 7 ( \mathbf { 1 2 . 0 7 } )}$ & $<\mathbf{0 . 0 0 1}$ \\
Size & $1.47-1.87$ & $1.64(0.08)$ & $1.45-1.85)$ & $1.64(0.09)$ & $\mathbf{0 . 4 9 8}$ \\
BMI & $18.50-40.00$ & $\mathbf{2 7 . 7 2 ( 4 . 9 4 )}$ & $17.60-45.70$ & $\mathbf{2 5 . 7 1 ( 4 . 4 0 )}$ & $<\mathbf{0 . 0 0 1}$ \\
\hline
\end{tabular}

${ }^{*} \mathrm{SD}=$ standard deviation.

Table 3. Association between migraine and BMI, Parakou 2017.

\begin{tabular}{ccccccccc}
\hline \multirow{2}{*}{ BMI $\left(\mathrm{kg} / \mathrm{m}^{2}\right)$} & \multicolumn{2}{c}{ Migraine } & \multicolumn{2}{c}{ No migraine } & & \multirow{2}{*}{ OR } & IC $_{95 \%}$ & $\mathrm{p}$ \\
\cline { 2 - 5 } & $\mathrm{n}$ & $\%$ & $\mathrm{n}$ & $\%$ & & & \\
\hline$\geq 30$ & 24 & $\mathbf{5 4 . 5}$ & 20 & 45.5 & 4.4 & $(2.0-9.5)$ & $<0.001$ \\
$25-29.9$ & 23 & 34.8 & 43 & 65.2 & 1.9 & $(1.1-3.9)$ & 0.03 \\
$<25$ & 19 & 21.6 & 69 & 78.4 & 1 & & \\
\hline
\end{tabular}

Table 4. Obesity and clinical charachteristics of migraine, Parakou 2017.

\begin{tabular}{cccc}
\hline Clinical characteristics & Migraine population N (\%) & Obesity N (\%) & $\mathbf{p}$ \\
\hline Number of crisis in last month & 20 & & \\
Unknown & 10 & $5(35.0)$ & 0.615 \\
$<3$ & 36 & $12(33.3)$ & \\
$\geq 3$ & & & \\
In last 6 months & 33 & $13(39.4)$ & 0.505 \\
Unknown & 10 & $2(20.0)$ & \\
$<5$ & 23 & $9(39.1)$ & \\
$\geq 5$ & & & \\
Migraine type & 37 & $14(37.8)$ & 0.775 \\
Without aura & 29 & $10(34.5)$ & \\
With aura & & &
\end{tabular}

found with adipose tissue distribution [14]. After adjustment for age and compared with women without a history of migraine and with a BMI $<23.0$ $\mathrm{kg} / \mathrm{m}^{2}$, increasing BMI has been associated with increased risk of any history of migraine. The causal relationship is not known, but obesity and migraine share overlapping central and peripheral mechanisms that may contribute to their association [12]. Connection of neurotransmitters and proteins between migraine and satiety have been etablished in some studies [14]. Role of hypothalamus in central regulation of diet [15] and also in the genesis of migraine [5], as well as the common pathways of activation/inhibition and the interaction of neurotransmitters such as serotonin and orexin peptides have already been highlighted in the literature. Also adipocytokines such as ADP [16] 
and leptin [17] which are proteins produced by adipocytes, but also by several other tissues including the brain have been implicated in the modulation of inflammation and pain. As with migraine, ADP exhibits a sexual dimorphism [18] and leptin is inhibited by testosterone and increased by ovarian sex steroids, with women exhibiting levels 2 - 3 times higher than men even when matched for age and BMI. Also obese individuals generally exhibit high circulating concentration of leptin, suggesting leptin resistance in states of obesity [19].

In our study, obesity has been not associated to the clinical characteristics of migraine. Contrary in the literature, total body obesity is associated with an increased risk of transforming episodic migraine to chronic [4]. This difference can be explained by the samll size of the sample of migraine sufferers.

Therapeutically, after bariatric surgical for weight loss, patients who have achieved greater weight loss has greater odds of experiencing a $\geq 50 \%$ reduction in headache frequency and a reduction of disability [20]. It is also possible that several downstream mechanisms may also be at play when loss weight, such as favorable changes in inflammatory cytokines and adipokines, improved psychological symptoms (e.g., depression), or behavioral activity. We know now that inactivity increases by $21 \%$ the risk of headache attacks in adult migraineurs (hazard ratio 1.209; $\mathrm{P}<0.01$ ) [21] and a 50\% increase risk of migraine in adolescents (odds ratio 1.5; 95\% CI: 1.0 - 2.2) [22]. Some R-Controlled Clin Trial have focused on the impact of weight reduction alone or with diet. Lemstra after 6 weeks of physical activity ( 3 times a week) associated with diet, relaxation and other stress managment techniques with 80 migraineurs, found pain frequency decreased by $33.64 \% \pm 5.29 \%, \mathrm{P}=0.000$ [23]. In Darabaneanu prospective study on 16 episodic migraineurs, average number of headache days per month has decreased after 10 weeks of exercise, $(P=0.048)$ and significant decreases has been seen in the duration and intensity of the migraine attacks [24]. On the other hand Dittrich has found with 30 women migraineurs no significant difference in change in migraine attack frequency after 6 weeks of physical exercise only [25]. In light of these studies, moderate physical exercise and diet are key weight loss strategies and are often recommended to migraine patients.

\section{Conclusion}

From this case-control study on obesity and migraine, it appears that migraine is significantly associated with obesity and overweight; the clinical features of migraine were not associated to body mass index.

\section{Conflicts of Interest}

The authors declare no conflicts of interest regarding the publication of this paper.

\section{References}

[1] Gelber, R.P., Gaziano, J.M., Orav, E.J., Manson, J.E., Buring, J.E. and Kurth, T. 
(2008) Measures of Obesity and Cardiovascular Risk among Men and Women. Journal of the American College of Cardiology, 52, 605-615. https://doi.org/10.1016/j.jacc.2008.03.066

[2] Stovner, L., Hagen, K., Jensen, R., et al. (2007) The Global Burden of Headache: A Documentation of Headache Prevalence and Disability Worldwide. Cephalalgia, 27, 193-210. https://doi.org/10.1111/j.1468-2982.2007.01288.x

[3] Ashkenazi, A. and Silberstein, S.D. (2006) Hormone-Related Headache: Pathophysiology and Treatment. CNS Drugs, 20, 125-141. https://doi.org/10.2165/00023210-200620020-00004

[4] Bigal, M.E. and Lipton, R.B. (2006) Obesity Is a Risk Factor for Transformed Migraine But Not Chronic Tensiontype Headache. Neurology, 67, 252-257. https://doi.org/10.1212/01.wnl.0000225052.35019.f9

[5] Denuelle, M., Fabre, N., Payoux, P., Chollet, F. and Geraud, G. (2007) Hypothalamic Activation in Spontaneous Migraine Attacks. Headache, 47, 1418-1426. https://doi.org/10.1111/j.1526-4610.2007.00776.x

[6] Peterlin, B.L. and Rapoport, A.M. (2007) Clinical Pharmacology of the Serotonin Receptor Agonist, Zolmitriptan. Expert Opinion on Drug Metabolism \& Toxicology, 3, 899-911. https://doi.org/10.1517/17425255.3.6.899

[7] Berilgen, M.S., Bulut, S., Gonen, M., et al. (2005) Comparison of the Effects of Amitriptyline and Flunarizine on Weight Gain and Serum Leptin, C Peptide and Insulin Levels When Used as Migraine Preventive Treatment. Cephalalgia, 25, 1048-1053. https://doi.org/10.1111/j.1468-2982.2005.00956.x

[8] Guldiken, B., Guldiken, S., Demir, M., Turgut, N. and Tugrul, A. (2008) Low Leptin Levels in Migraine: A Case Control Study. Headache, 40, 1103-1107. https://doi.org/10.1111/j.1526-4610.2008.01152.x

[9] Tilg, H. and Moschen, A.R. (2006) Adipocytokines: Mediators Linking Adipose Tissue, Inflammation and Immunity. Nature Reviews Immunology, 6, 772-783. https://doi.org/10.1038/nri1937

[10] Weisberg, S.P., McCann, D., Desai, M., Rosenbaum, M., Leibel, R.L. and Ferrante Jr., A.W. (2003) Obesity Is Associated with Macrophage Accumulation in Adipose Tissue. Journal of Clinical Investigation, 112, 1796-1808. https://doi.org/10.1172/JCI200319246

[11] Lucas, C., Géraud, G., Valade, D., Chautard, M.-H. and Lantéri-Minet, M. (2006) Recognition and Therapeutic Management of Migraine in 2004, in France: Results of FRAMIG 3, a French Nationwide Population-Based Survey. Headache, 46, 715-725. https://doi.org/10.1111/j.1526-4610.2006.00430.x

[12] Chai, N.C., Scher, A.I., Moghekar, A., Bond, D.S. and Peterlin, B.L. (2014) Obesity and Headache: Part I. A Systematic Review of the Epidemiology of Obesity and Headache. Headache, 54, 219-234. https://doi.org/10.1111/head.12296

[13] Evans, R.W., Williams, M.A., Rapoport, A.M. and Peterlin, B.L. (2012) The Association of Obesity with Episodic and Chronic Migraine. Headache, 52, 663-671. https://doi.org/10.1111/j.1526-4610.2012.02114.x

[14] Peterlin, B.L., Rosso, A.L., Rapoport, A.M. and Scher, A.I. (2010) Obesity and Migraine: The Effect of Age, Gender and Adipose Tissue Distribution. Headache, 50, 52-62. https://doi.org/10.1111/j.1526-4610.2009.01459.x

[15] Bray, G.A. (2005) Drug Insight: Appetite Suppressants. Nature Clinical Practice Gastroenterology \& Hepatology, 2, 89-95. https://doi.org/10.1038/ncpgasthep0092

[16] Peterlin, B.L., Bigal, M.E., Tepper, S.J., Urakaze, M., Sheftell, F.D. and Rapoport, 
A.M. (2007) Migraine and Adiponectin: Is There a Connection? Cephalalgia, 27, 435-446. https://doi.org/10.1111/j.1468-2982.2007.01306.x

[17] Kutlu, S., Canpolat, S., Sandal, S., Ozcan, M., Sarsilmaz, M. and Kelestimur, H. (2003) Effects of Central and Peripheral Administration of Leptin on Pain Threshold in Rats and Mice. Neuro Enocrinology Letters, 24, 193-196.

[18] Tsatsanis, C., Zacharioudaki, V., Androulidaki, A., et al. (2005) Adiponectin Induces TNF-alpha and IL-6 in Macrophages and Promotes Tolerance to Itself and Other Pro-Inflammatory Stimuli. Biochemical and Biophysical Research Communications, 335, 1254-1263. https://doi.org/10.1016/j.bbrc.2005.07.197

[19] Matsubara, M., Maruoka, S. and Katayose, S. (2002) Inverse Relationship between Plasma Adiponectin and Leptin Concentrations in Normal-Weight and Obese Women. European Journal of Endocrinology, 147, 173-180. https://doi.org/10.1530/eje.0.1470173

[20] Bond, D.S., Vithiananthan, S., Nash, J.M., Thomas, J.G. and Wing, R.R. (2011) Improvement of Migraine Headaches in Severely Obese Patients after Bariatric Surgery. Neurology, 76, 1135-1138. https://doi.org/10.1212/WNL.0b013e318212able

[21] Wober, C., Brannath, W., Schmidt, K., et al. (2007) Prospective Analysis of Factors Related to Migraine Attacks: The PAMINA Study. Cephalalgia, 27, 304-314. https://doi.org/10.1111/j.1468-2982.2007.01279.x

[22] Robberstad, L., Dyb, G., Hagen, K., Stovner, L.J., Holmen, T.L. and Zwart, J.A. (2010) An Unfavorable Lifestyle and Recurrent Headaches among Adolescents: The HUNT Study. Neurology, 75, 712-717. https://doi.org/10.1212/WNL.0b013e3181 eee244

[23] Lemstra, M., Stewart, B. and Olszynski, W.P. (2002) Effectiveness of Multidisciplinary Intervention in the Treatment of Migraine: A Randomized Clinical Trial. Headache, 42, 845-854. https://doi.org/10.1046/j.1526-4610.2002.02202.x

[24] Darabaneanu, S., Overath, C.H., Rubin, D., et al. (2011) Aerobic Exercise as a Therapy Option for Migraine: A Pilot Study. International Journal of Sports Medicine, 32, 455-460. https://doi.org/10.1055/s-0030-1269928

[25] Dittrich, S.M., Gunther, V., Franz, G., Burtscher, M., Holzner, B. and Kopp, M. (2008) Aerobic Exercise with Relaxation: Influence on Pain and Psychological Well-Being in Female Migraine Patients. Clinical Journal of Sport Medicine, 18, 363-365. https://doi.org/10.1097/JSM.0b013e31817efac9 